\title{
Identification of novel medulloblastoma cell-targeting peptides for use in selective chemotherapy drug delivery
}

Kristel C. Tjandra ${ }^{2,5}$, Nigel McCarthy ${ }^{1}$, Lu Yang${ }^{1}$, Alistair J. Laos ${ }^{2,5}$, George Sharbeen ${ }^{4}$, Phoebe A Phillips ${ }^{2,4}$, Helen Forgham ${ }^{1,2,3}$, Sharon M Sagnella ${ }^{1}$, Renee M Whan ${ }^{2,6}$, Maria Kavallaris ${ }^{1,2,3 *}$, Pall Thordarson ${ }^{2,5 *}$, Joshua A McCarroll1,2,3*

1. Tumour Biology \& Targeting Program, Children's Cancer Institute, Lowy Cancer Research Centre, UNSW Sydney, NSW, Australia, 2031.

2. Australian Centre for Nanomedicine, ARC Centre of Excellence in Convergent Bio-Nano Science \& Technology, UNSW Sydney, NSW, Australia, 2052.

3. School of Women's and Children's Health, Faculty of Medicine, UNSW Sydney, NSW, Australia, 2052.

4. Pancreatic Cancer Translational Research Group, Lowy Cancer Research Centre, School of Medical Sciences, UNSW Sydney, NSW, Australia, 2052.

5. School of Chemistry, UNSW Sydney, NSW, Australia, 2052.

6. Biomedical Imaging Facility Mark Wainwright Analytical Centre, UNSW Sydney, NSW, Australia, 2052.

* Corresponding authors. 


\section{Supplementary Information}

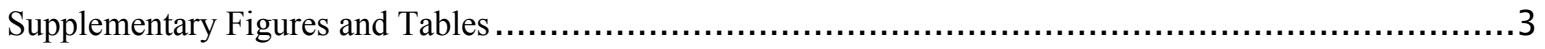

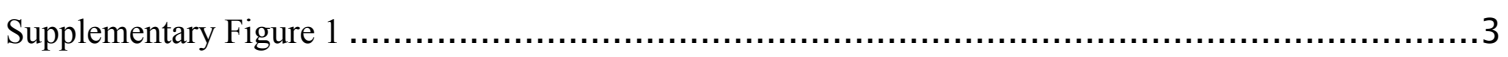

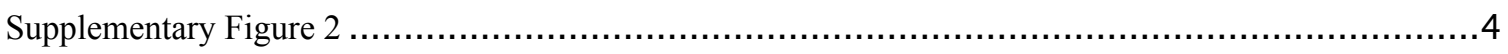

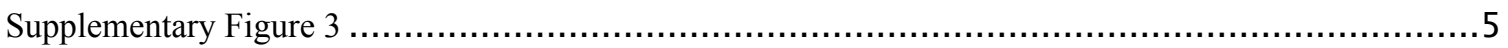

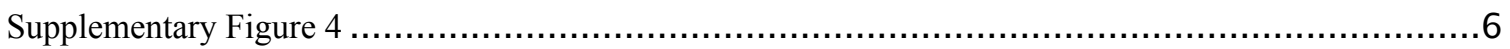

Matrix Assisted Laser Desorption / Ionization Time-of-Flight (MALDI-TOF) Mass Spectrometry

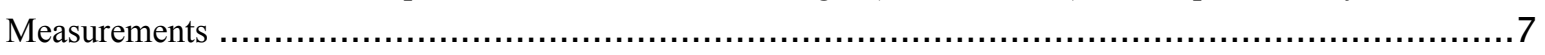

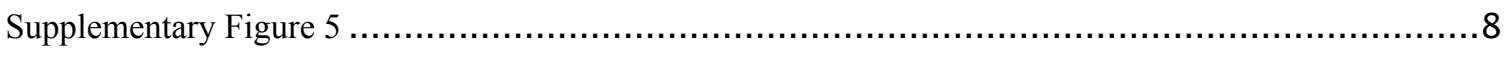

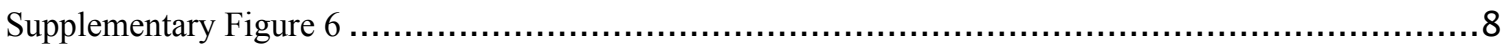

Supplementary Table 1. E1-3 Conjugate LCMS/MS analyte analysis based on linear regression of the

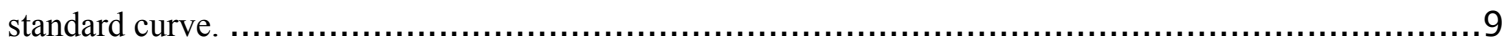

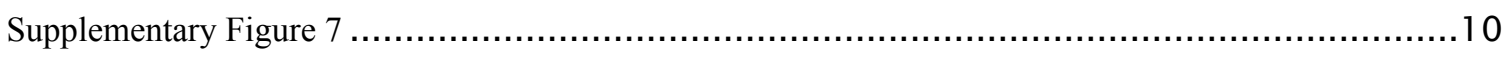

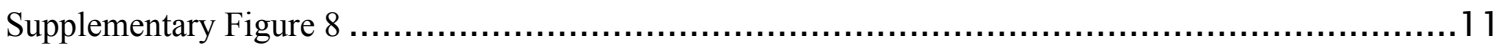

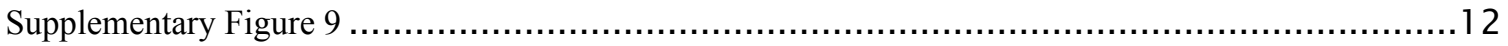

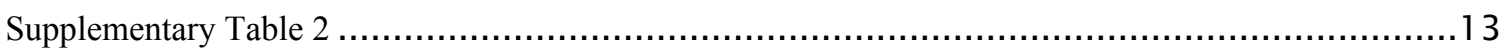

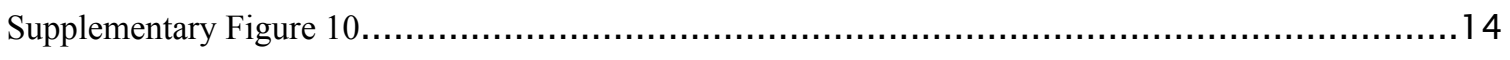

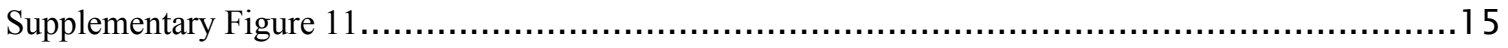

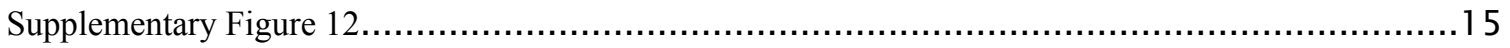

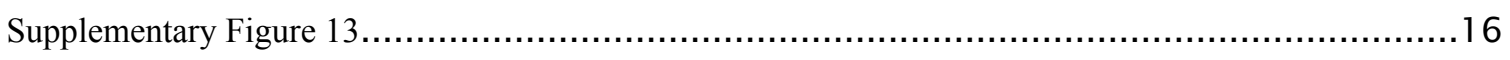

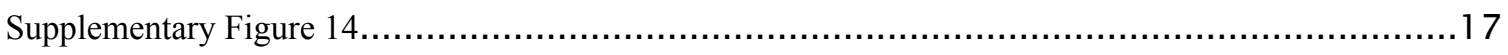

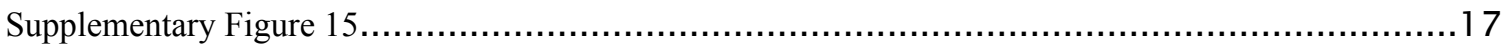

Characterization Data of Peptide-Drug Conjugates ............................................................ 18

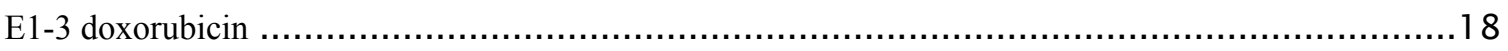

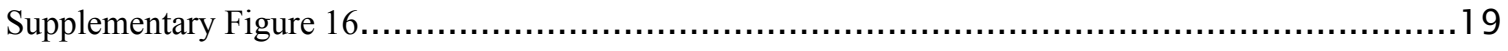

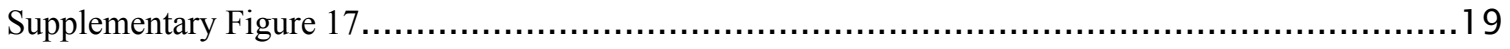

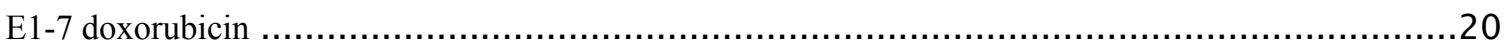

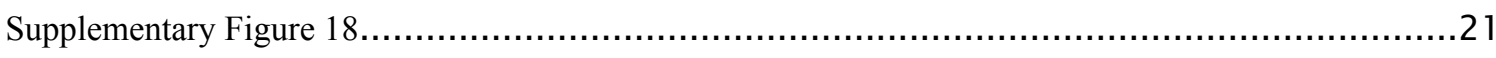

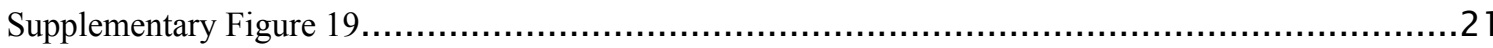




\section{Supplementary Figures and Tables}

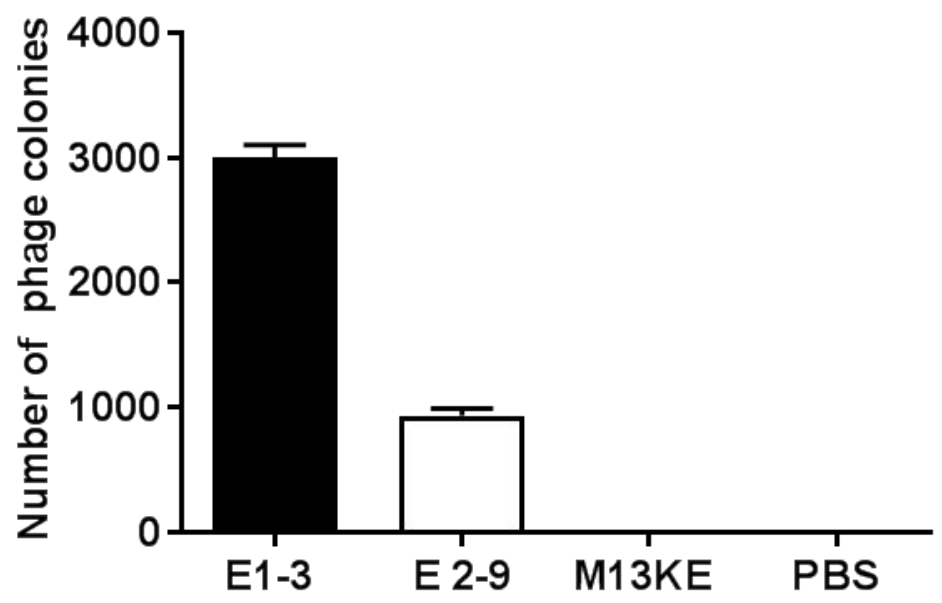

Supplementary Figure 1. E1-3 and E2-9 bacteriophage cell binding affinity to medulloblastoma cells. Graph showing that a higher number of purified E1-3 bacteriophages $\left(5 \times 10^{9} \mathrm{pfu}\right)$ bind to the surface of medulloblastoma cells compared to E2-9 bacteriophages $\left(5 \times 10^{9} \mathrm{pfu}\right)$. Cells exposed to M13KE or PBS served as controls, $n=3$ separate experiments, $p<0.05$. 


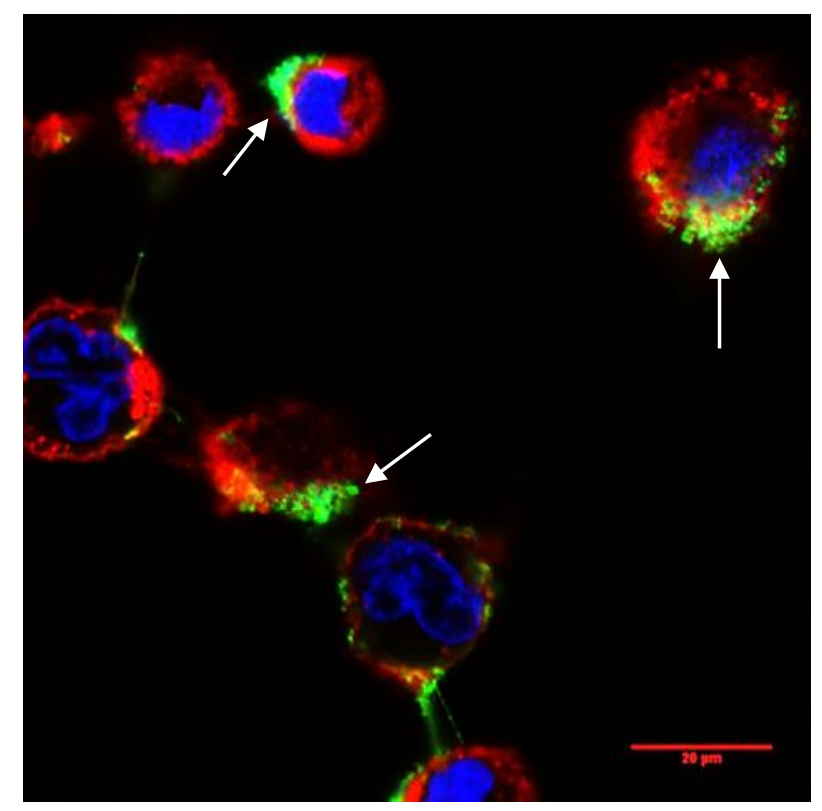

Supplementary Figure 2. E1-3 peptide (1) binds to the cell surface of medulloblastoma cells. Representative live cell confocal microscope image of fluorescently labelled E1-3 peptide bound to the cell surface of medulloblastoma cells 15 minutes post-treatment. Red = cell membrane, Blue = nucleus, Green = E1-3 peptide (1). White arrows indicate E1-3 peptide (1). Scale bar $=20 \mu m$. 


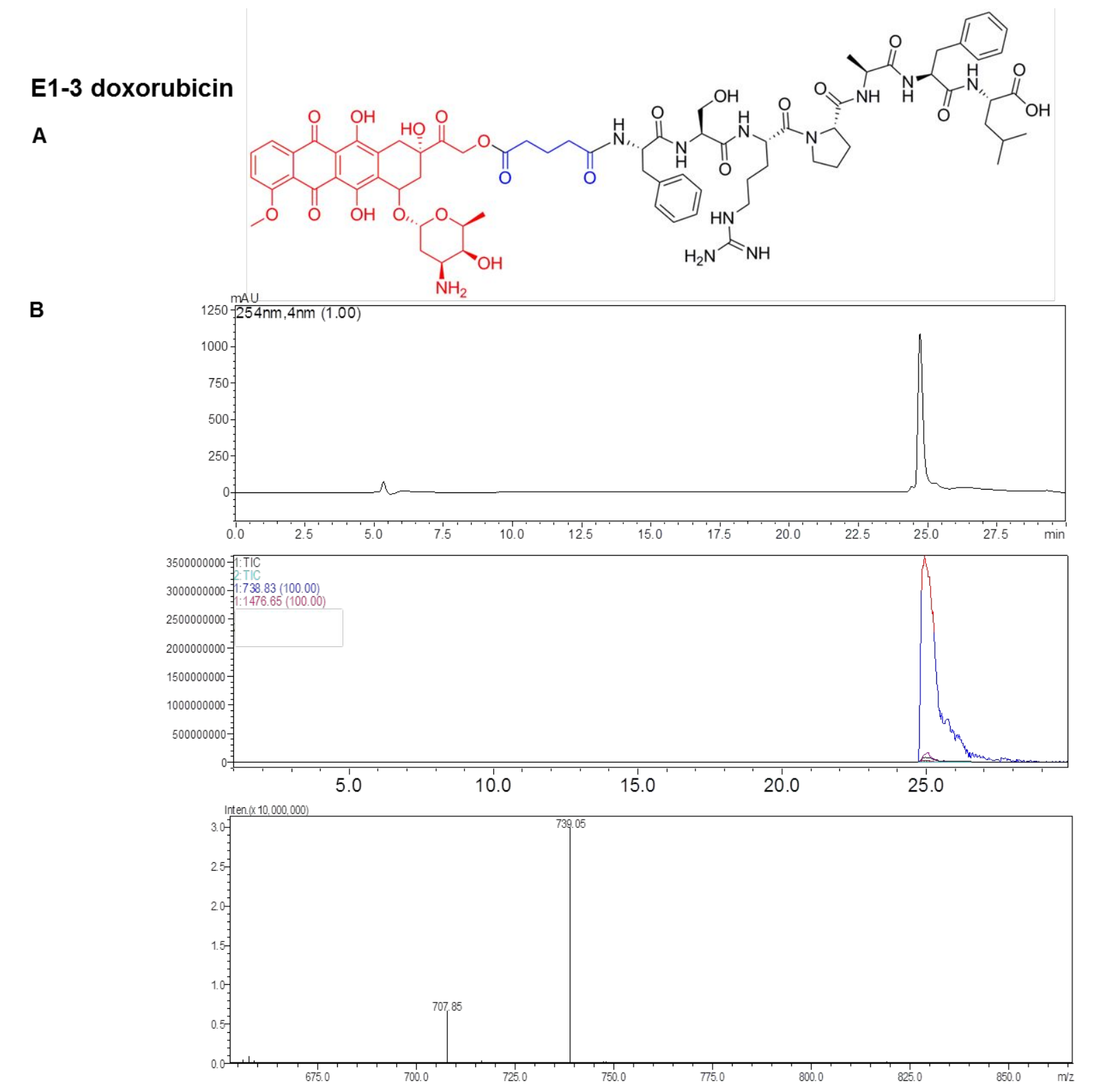

\section{Supplementary Figure 3. LC/MS characterization of E1-3 doxorubicin conjugate (3). A)}

Structure of E1-3 doxorubicin conjugate (3). B) UV chromatogram of E1-3 doxorubicin (3) collected using liquid chromatography (LC, top), extracted ion chromatogram from the total ion count indicating the presence of desired compound at the same retention time as the chromatogram (at 25 minutes) matching the $[\mathrm{M}+\mathrm{H}]^{+}$and $[\mathrm{M}+2 \mathrm{H}]^{2+}$ species (middle), and the mass spectra of the compound showing the $[\mathrm{M}+2 \mathrm{H}]^{+}$species at $\mathrm{m} / \mathrm{z} 739.05$. 
E1-7 doxorubicin

A

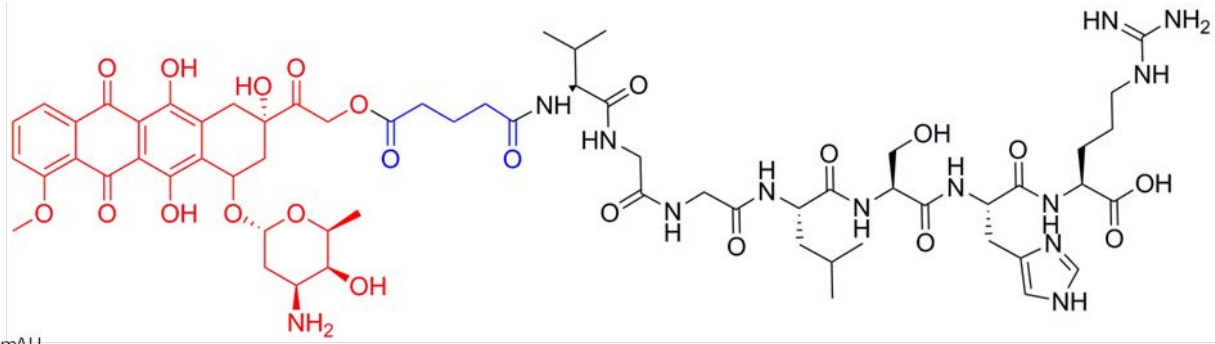

B
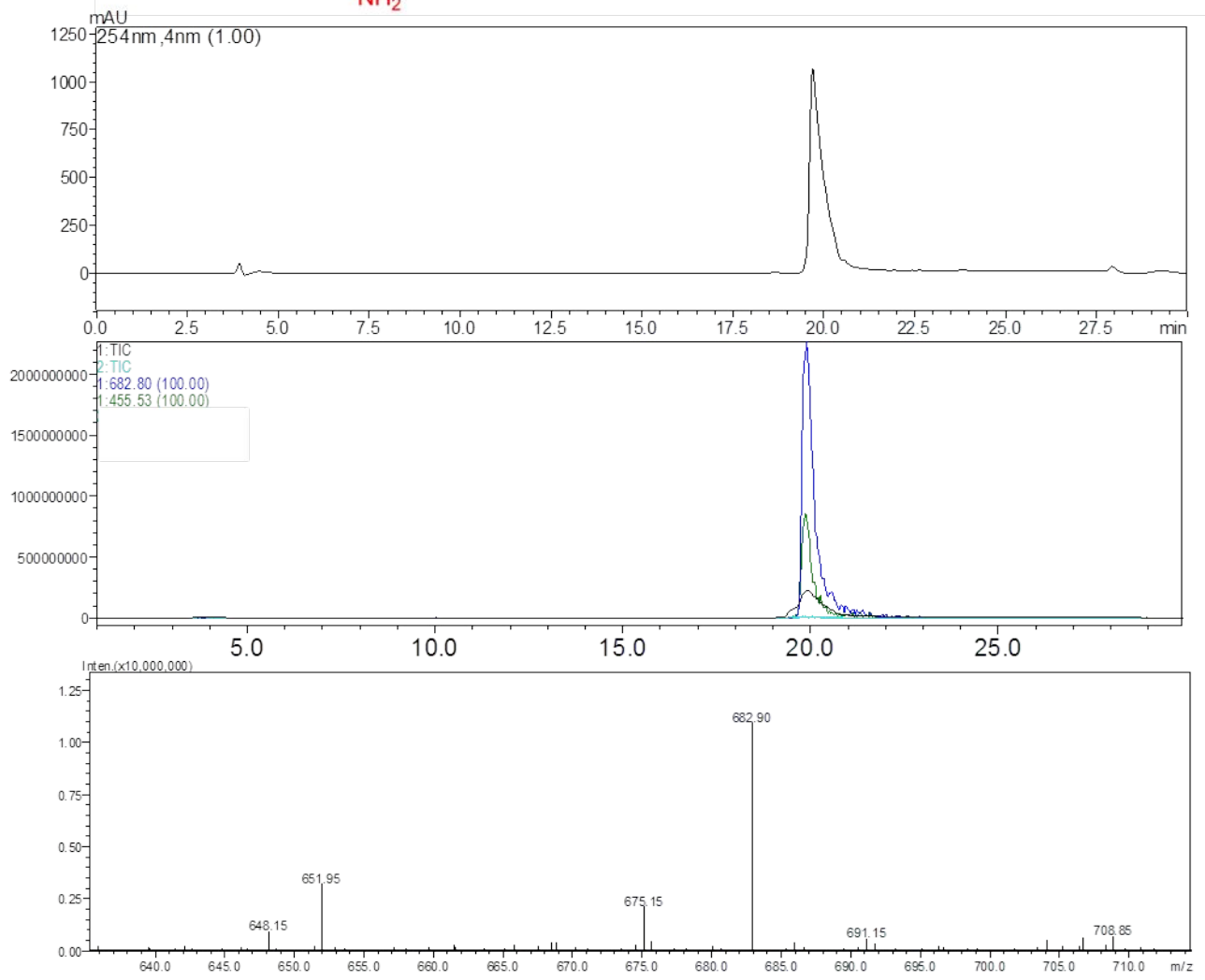

Supplementary Figure 4. LC/MS characterization of E1-7 doxorubicin conjugate (4). A)

Structure of E1-7 doxorubicin conjugate (4). B) UV chromatogram of E1-7 doxorubicin (4) collected using liquid chromatography (top), extracted ion chromatogram from the total ion count indicating the presence of desired compound at the same retention time as the chromatogram (at 20 minutes), matching the $[M+2 H]^{+}$and $[M+3 H]^{3+}$ species (middle), and the mass spectra of the compound showing $[\mathrm{M}+2 \mathrm{H}]^{+}$species at $\mathrm{m} / \mathrm{z} 682.90$. 


\section{Matrix Assisted Laser Desorption / Ionization Time-of-Flight (MALDI-TOF) Mass Spectrometry Measurements}

Matrix-Assisted Laser Desorption Ionization Time-of-Flight (MALDI-TOF) Mass Spectrometry measurements in this study were performed on a Bruker ultrafleXtreme mass spectrometer. Samples were analysed in a matrix consisting of 2,5-dihydroxybenzoic acid (50 $\mathrm{mg} / \mathrm{mL})$ and 2-hydroxy-5-methoxybenzoic acid mixture (9:1) dissolved in an aqueous solution of acetonitrile and $0.1 \%(\mathrm{v} / \mathrm{v})$ aqueous trifluoroacetic acid $(1: 1, \mathrm{v} / \mathrm{v})$. Small portions $(1 \mu \mathrm{L})$ of dilute $\left(10^{-4}\right.$ to $\left.10^{-6} \mathrm{M}\right)$ solutions of each compound in acetonitrile/water were added with 1-2 $\mu \mathrm{L}$ of the matrix and deposited onto a 384-ground steel sample plate and air-dried for analysis. The instrument was calibrated with a low molecular weight peptide calibrant.

\section{Stability of Peptide-Doxorubicin Conjugates in Human and Mouse Serum}

Serum stability tests for the E1-3 doxorubicin conjugate (3) in both human and mouse serum was performed using LCMS/MS (Thermo Scientific LTQ Orbitrap XL connected to an Accela liquid chromatography system) and MALDI-TOF mass spectrometry (Bruker ultrafleXtreme).

For the LCMS/MS measurement, a calibration curve was constructed for the E1-3 doxorubicin conjugate (3) using free doxorubicin (5) $(6 \mu \mathrm{M})$ as an internal standard. E1-3 doxorubicin (3) calibration solutions in acetonitrile/water $(1: 1, \mathrm{v} / \mathrm{v})$ concentrations of $1,2.5$, 5, 10, $17 \mu \mathrm{M}$ were pre-mixed with free doxorubicin $(5)(6 \mu \mathrm{M})$ in acetonitrile/water $(1: 1, \mathrm{v} / \mathrm{v})$ solution. Each calibration solution $(20 \mu \mathrm{L})$ was injected onto LCMS/MS with $0.1 \%$ formic acid in acetonitrile (B) and $0.1 \%$ formic acid in water (A) as eluent. The following gradient elution profile was followed: $t=0-5 \min .5 \% \mathrm{~B} ; t=5-20 \min$. gradient $5-100 \% \mathrm{~B} ; t=22$ - 25 min. 100\% B; $t=25.5-30$ min. 5\% B. Under this condition, E1-3 doxorubicin (3) 
eluted at $\mathrm{t}=11.06$ minutes while free doxorubicin (5) eluted at $\mathrm{t}=10.23$ minutes (Supplementary Figure 5). The area ratio of the E1-3 doxorubicin conjugate (3) vs. the free doxorubicin (5) from the extracted ion chromatograms was plotted against the concentration of the E1-3 doxorubicin conjugate (3) to produce a standard calibration curve (Supplementary Figure 6).

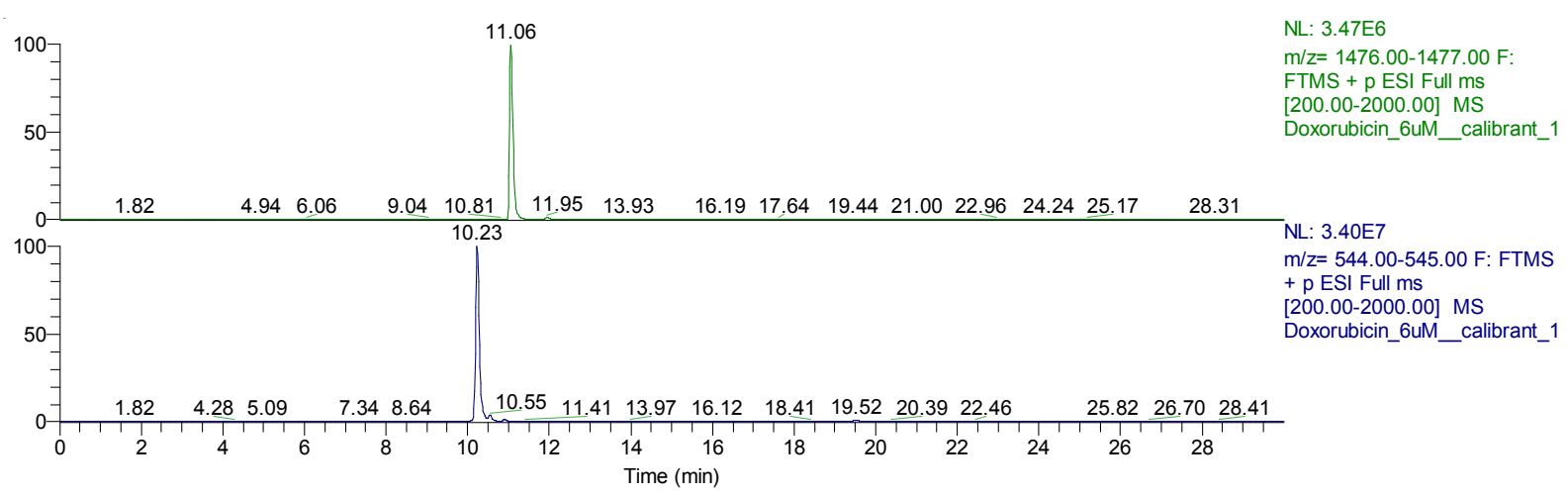

Supplementary Figure 5. Representative extracted ion chromatogram for E1-3 doxorubicin (3) (top) and doxorubicin (5) (bottom). Mass range $\mathrm{m} / \mathrm{z} 1476$ - 1477 for E1-3 doxorubicin (3) corresponds to the $[M+H]^{+}$species, while mass range $\mathrm{m} / z 544-545$ corresponds to the $[\mathrm{M}+\mathrm{H}]^{+}$of free doxorubicin (5).

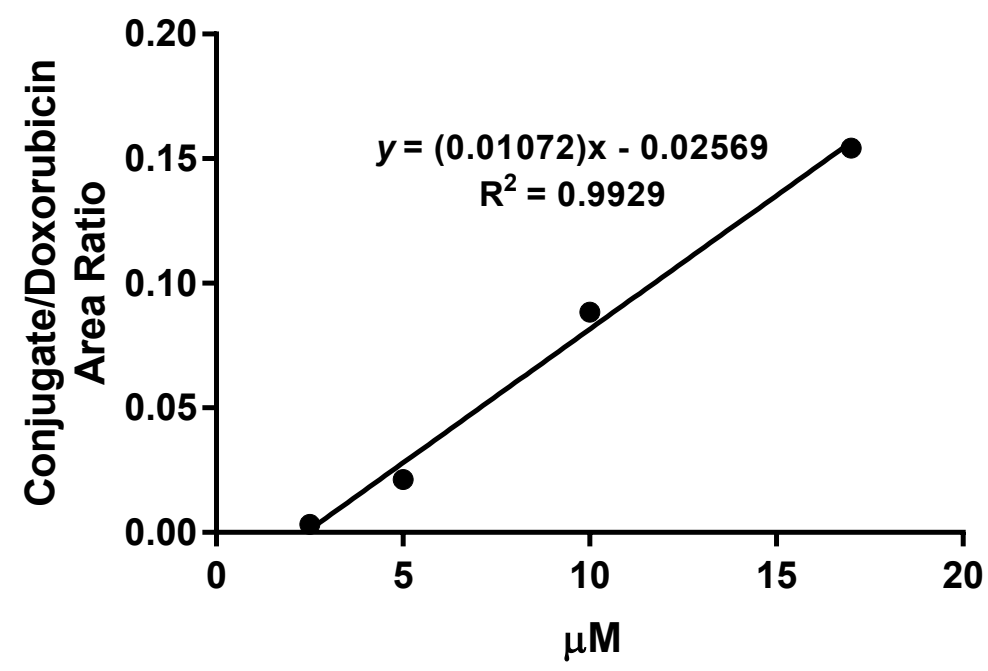

Supplementary Figure 6. Standard calibration curve for E1-3 doxorubicin conjugate (3) with doxorubicin (5) as internal standard. Linear regression analysis was performed on GraphPad Prism [Slope equation: $y=(0.01072) x-0.02569]$. 
For the serum stability test, E1-3 doxorubicin (3) solution in acetonitrile/water (1:1, v/v, 250 $\mu \mathrm{M})$ was incubated with solutions of mouse and human serum in phosphate buffered saline $(200 \mu \mathrm{L}, 1: 4, \mathrm{v} / \mathrm{v})$ in a $1: 1(\mathrm{v} / \mathrm{v})$ ratio. At $60,120,240$ minutes the compounds in the serum solutions $(50 \mu \mathrm{L})$ were collected and treated with acetonitrile $(250 \mu \mathrm{L})$ to precipitate any serum proteins in the samples. The precipitate was separated using centrifugation. The supernatant was then collected and analyzed on both LCMS/MS and MALDI-TOF MS. The supernatants were subjected to $1: 2$ dilution prior to injection into the LCMS/MS. The concentration of E1-3 doxorubicin (3) in the unknown supernatant samples was then calculated using the linear regression equation derived from the standard curve (Supplementary Table 1). The LCMS/MS result confirms the presence of intact E1-3 doxorubicin conjugate (3) after 4 hours. To validate these findings MALDI-TOF MS analysis was also performed. The supernatant containing the conjugate $(1 \mu \mathrm{L})$ were analysed using a 9:1 (w/w) mixture of DHB and 2-hydroxy-5-methoxybenzoic acid solution (super-DHB) (1 $\mu \mathrm{L})$ matrix. The detection of the $[\mathrm{M}+\mathrm{H}]^{+}$species indicated that the E1-3 doxorubicin conjugate remained intact after 4 hours incubation in both human or mouse serum (Supplementary Figure 7).

Supplementary Table 1. E1-3 Conjugate LCMS/MS analyte analysis based on linear regression of the standard curve.

\begin{tabular}{|c|c|c|c|c|c|}
\hline \multirow{3}{*}{ Serum } & $\begin{array}{c}\text { Incubation } \\
\text { Time (h) }\end{array}$ & $\begin{array}{c}\text { E1-3 } \\
\text { conjugate } \\
\text { Response } \\
\text { Area }\end{array}$ & $\begin{array}{c}\text { Free } \\
\text { Doxorubicin } \\
\text { (Internal Std.) } \\
\text { Response } \\
\text { Area }\end{array}$ & $\begin{array}{c}\text { E1-3 } \\
\text { conjugate/Doxorubicin } \\
\text { Area Ratio }\end{array}$ & $\begin{array}{c}\text { Calculated } \\
\text { E1-3 } \\
\text { conjugate } \\
\text { Conc. (uM) }\end{array}$ \\
\hline \multirow{3}{*}{ Human } & 1 & 1805571.70 & 180856259.03 & 0.009983463 & 3.33 \\
\cline { 2 - 6 } & 2 & 347513.80 & 306435135.24 & 0.001134053 & 2.50 \\
\hline \multirow{3}{*}{ Mouse } & 4 & 9985.16 & 601228441.86 & $1.66079 \mathrm{E}-05$ & 2.40 \\
\cline { 2 - 6 } & 2 & 55494.32 & 181019650.09 & 0.000306565 & 2.43 \\
\cline { 2 - 6 } & 4 & 512150.21 & 318342311.70 & 0.001608803 & 2.55 \\
\hline
\end{tabular}

*calculation is based on the linear regression equation: $\mathrm{y}=(0.01072) \mathrm{x}-0.02569$ 

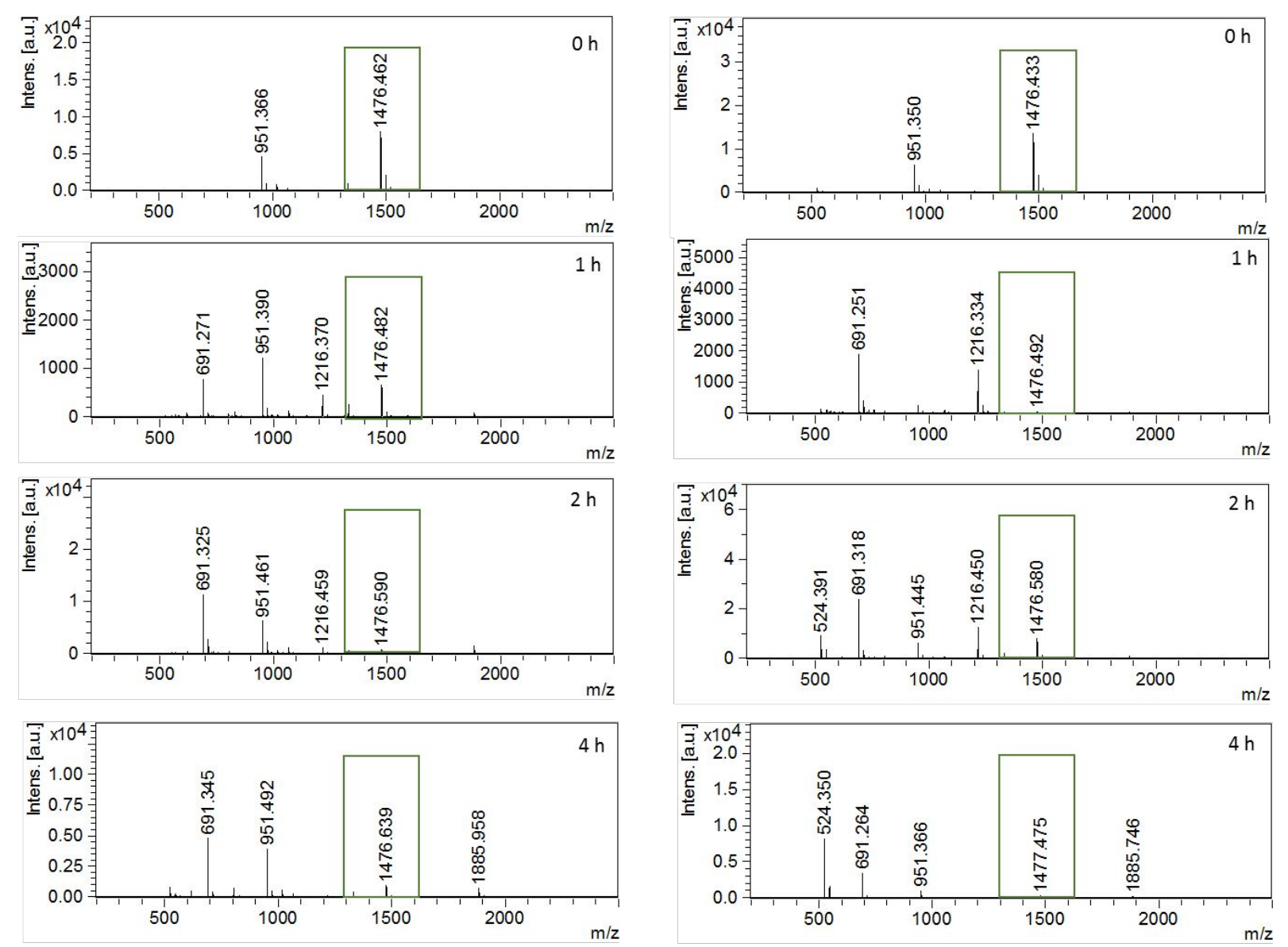

Human Serum

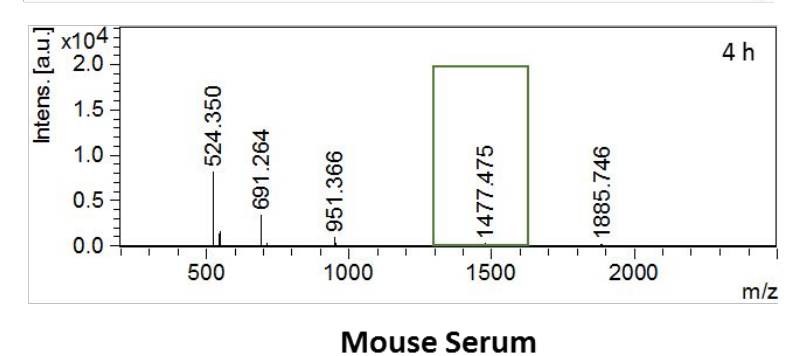

Supplementary Figure 7. Serum stability of E1-3 doxorubicin conjugate (3). $M A L D I-$ TOF mass spectra shows the presence of E1-3 doxorubicin (3) (250 $\mu$ M) after incubation in human serum (left hand column) or mouse serum (right hand column) for up to 4 hours. The desired $[\mathrm{M}+\mathrm{H}]^{+}$ion of E1-3 doxorubicin (3), calculated as $\mathrm{m} / \mathrm{z}$ 1476.65680, is highlighted by a green box. 
A

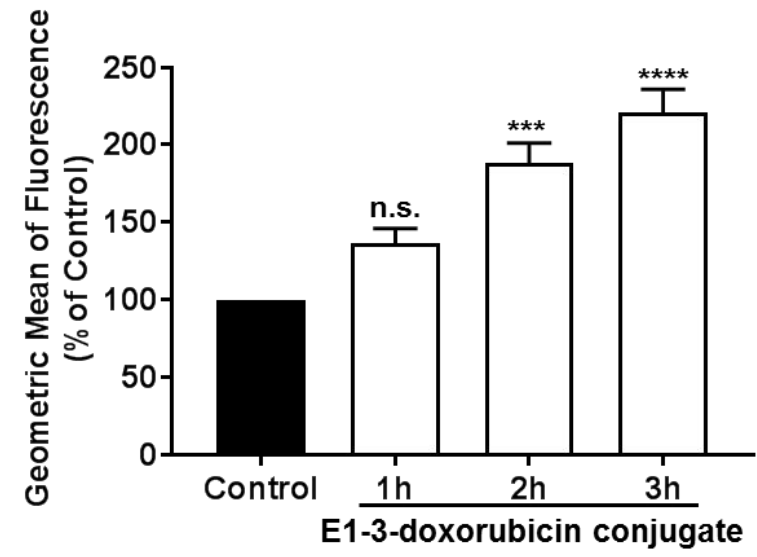

B

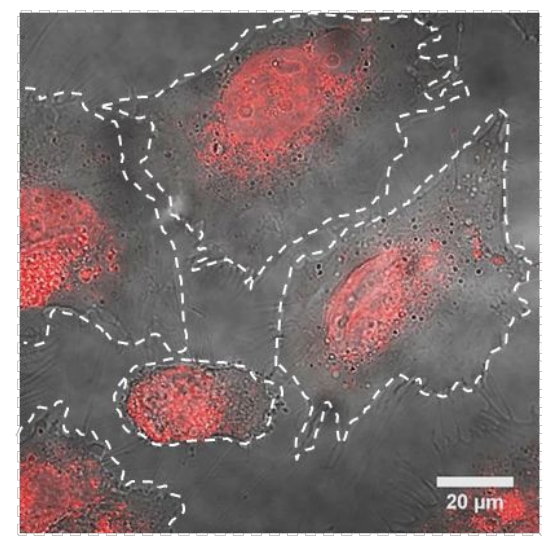

Supplementary Figure 8. E1-3 doxorubicin conjugate (3) accumulates into medulloblastoma cells. A) Graph demonstrating an increase in the accumulation of E1-3 doxorubicin conjugate (3) into medulloblastoma cells over a 3 hour time period. Cell uptake was measured by flow cytometry, $n=3$ independent experiments; *** $p=0.0003$, **** $p=$ 0.0001, n.s. (not significant). Error bars represent standard error of the mean $(n=3)$ ). B) Representative confocal microscope image of medulloblastoma cells showing peri-nuclear and nuclear localization of E1-3 doxorubicin conjugate (3) 3 hours post-treatment. 


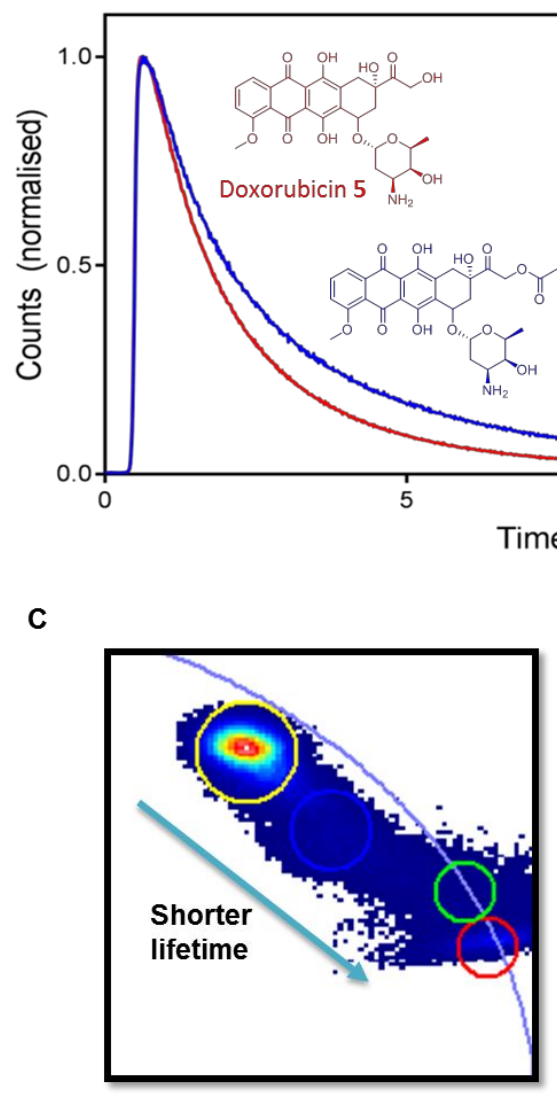

B
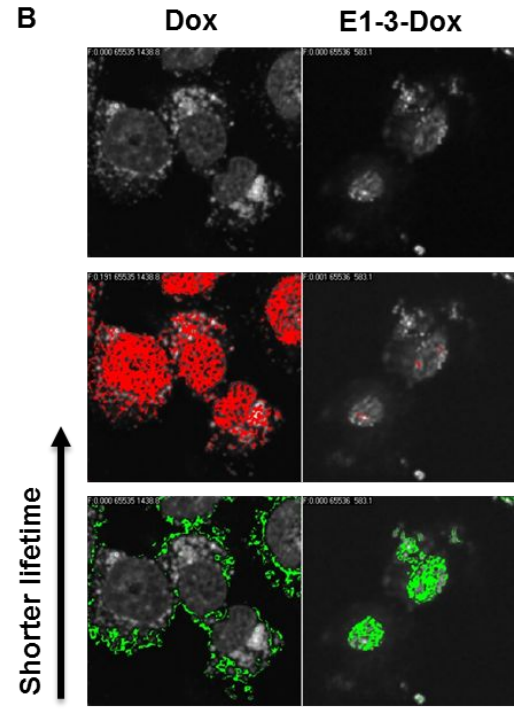

D

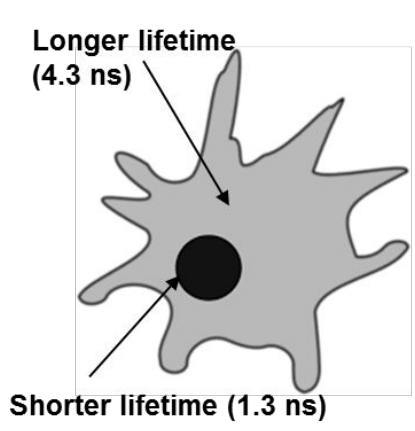

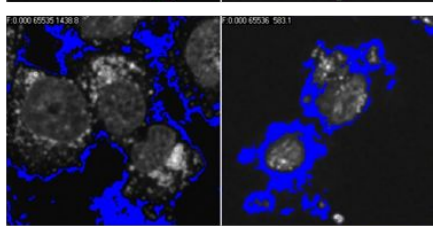

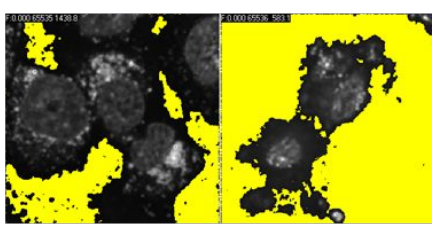

Supplementary Figure 9. Fluorescence lifetime images of E1-3 doxorubicin (3) and free doxorubicin (5) on medulloblastoma cells. A) Fluorescence lifetime decay of E1-3 doxorubicin conjugate (3) (Blue) and free doxorubicin (5) (Red). B) Fluorescence lifetime images from SIMFCS ${ }^{1}$, with phasor plot analysis-generated colour coding indicating the different fluorophore lifetime populations identified. C-D) Phasor plot analysis indicating longer lifetime population residing in the cytoplasmic compartment of the cell and shorter lifetime populations residing in the nuclear compartment of the cell in both images. 


\begin{tabular}{|c|c|c|c|}
\hline Compounds & $\begin{array}{c}\text { Medulloblastoma } \\
\text { cells (DAOY) }\end{array}$ & $\begin{array}{c}\text { Fibroblasts } \\
\text { (MRC5) }\end{array}$ & $\begin{array}{c}\text { Specificity Ratio } \\
\text { (IC50 } \\
\text { IC5RC5 }_{\text {DAOY }} /\end{array}$ \\
\hline Free Doxorubicin & $8.8 \pm 1.31$ & $148 \pm 1.15$ & $16.8 \pm 2.5$ \\
\hline E1-7 Doxorubicin & $130.0 \pm 1.27$ & $2523 \pm 2.48$ & $19.4 \pm 0.2$ \\
\hline $\begin{array}{c}\text { Overall } \\
\text { Specificity }\end{array}$ & & 1.2 \\
\hline
\end{tabular}

Supplementary Table 2. Free doxorubicin (5), E1-3 (3) and E1-7 (4) doxorubicin conjugate cytotoxic activity in non-tumor human fibroblasts. Table showing the IC50 values (nM) and specificity ratios for free doxorubicin (5), E1-3 doxorubicin conjugate (3) and E1-7 doxorubicin conjugate (4) in human fibroblasts (MRC5). IC50 values represent the mean \pm S.E.M from 3 independent experiments. 


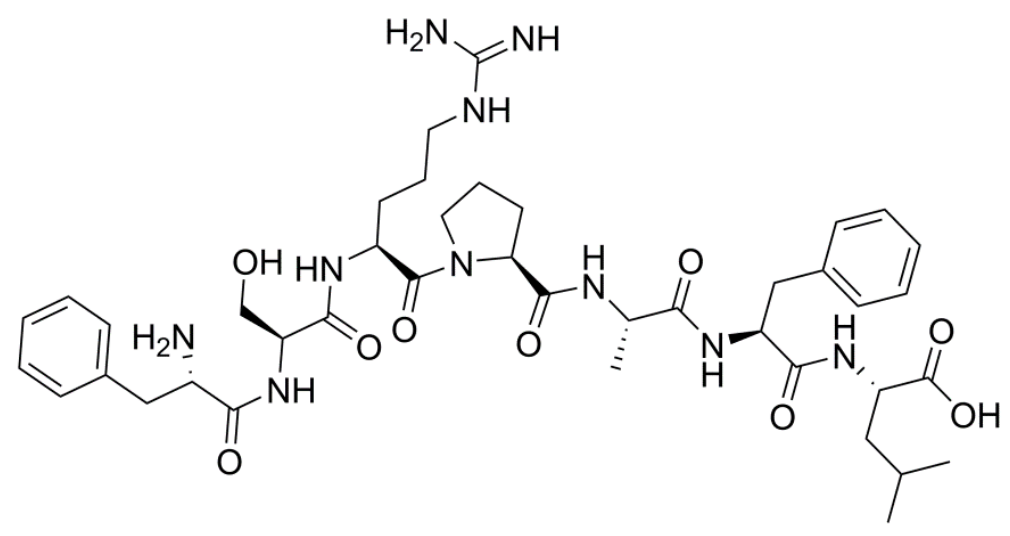

A
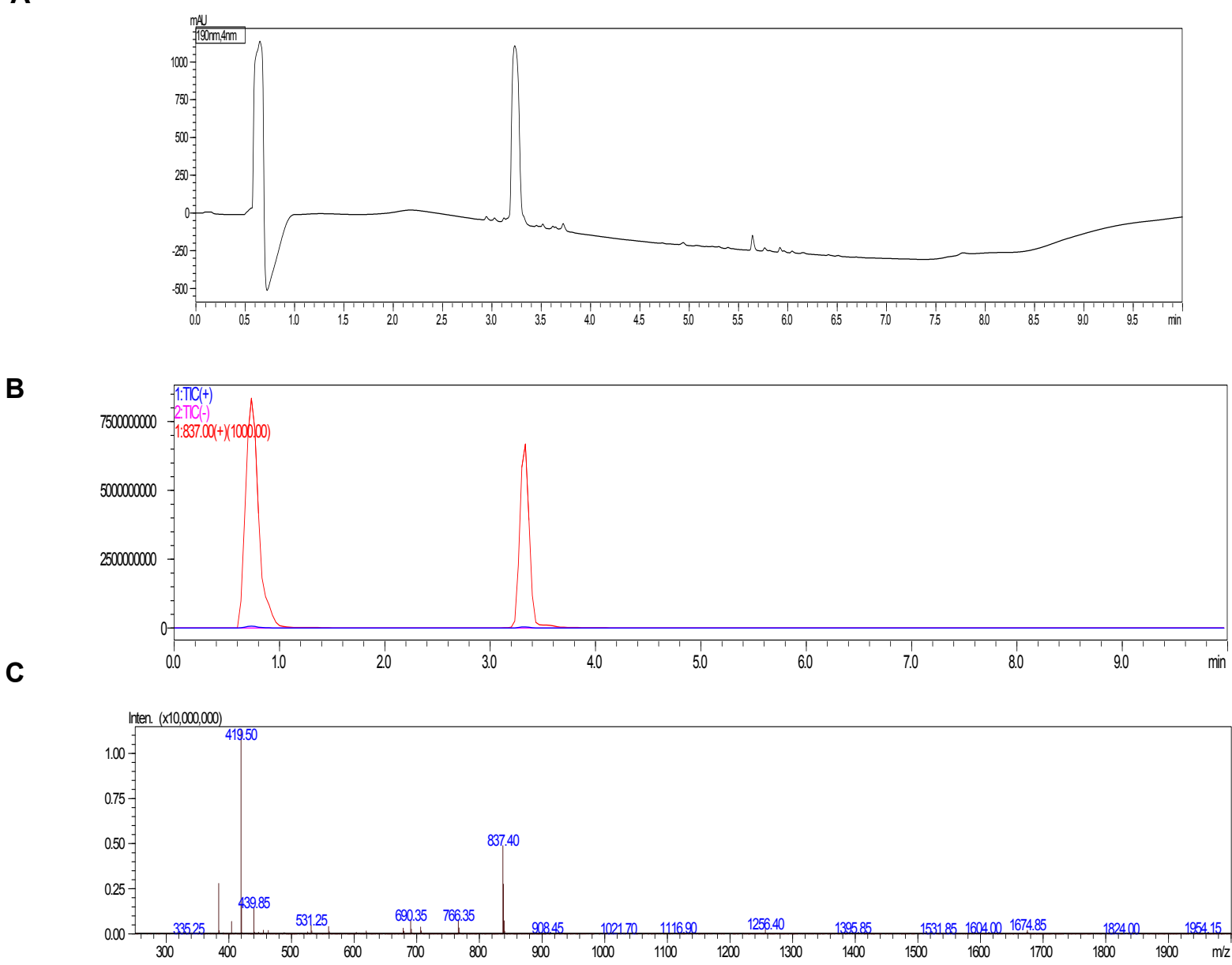

Supplementary Figure 10. LCMS measurement of Peptide E1-3 (1). (A) UV chromatogram of E1-3 peptide (1), (B) Mass spectrometry total ion count for $\mathrm{m} / \mathrm{z} 837.40$, which matches with the $[M+H]^{+}$for E1-3 peptide (1), and (C) Mass spectra of E1-3 peptide (1). 


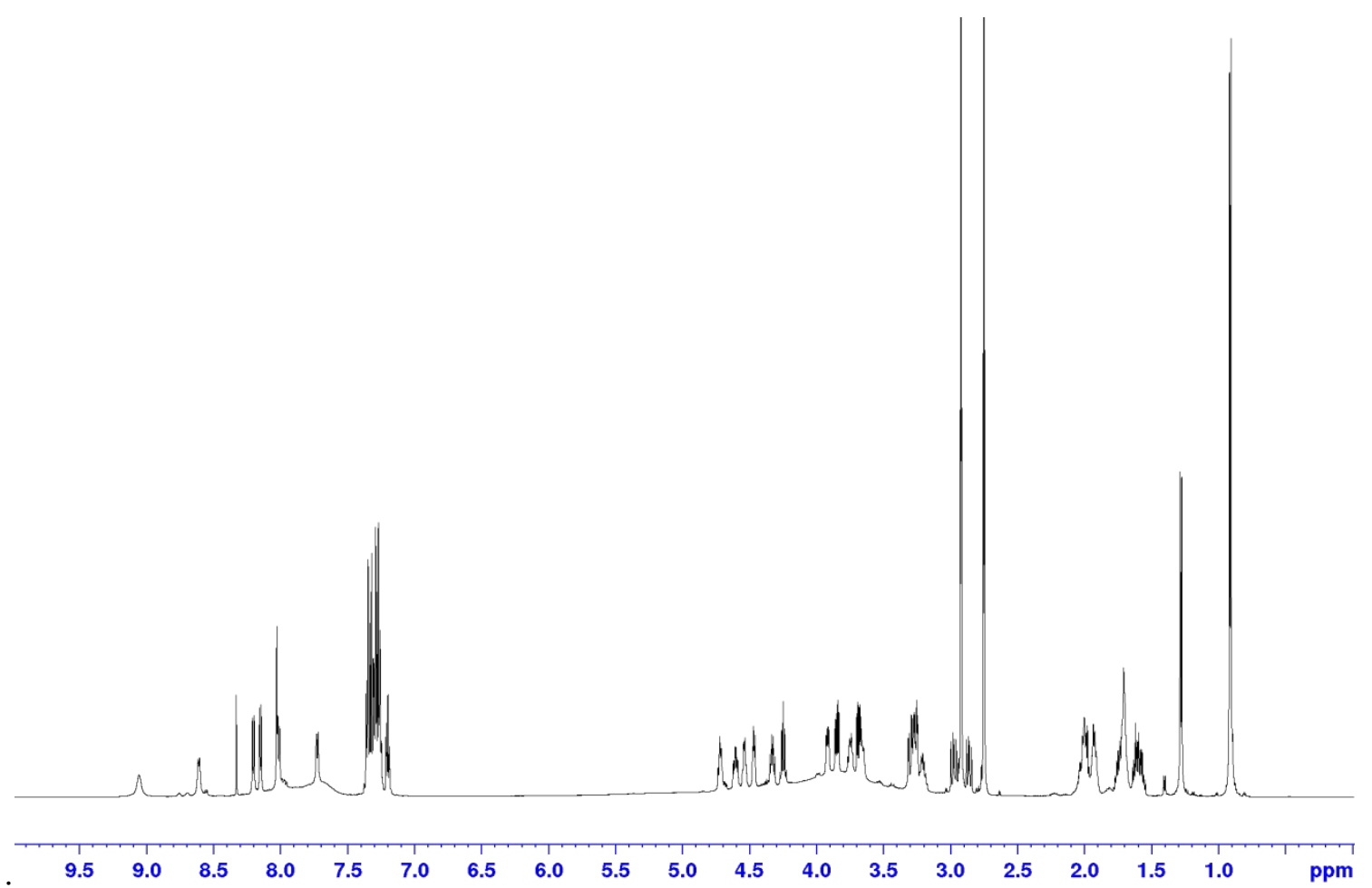

Supplementary Figure 11. ${ }^{1} \mathrm{H}$ NMR spectra (600 MHz) for E1-3 peptide (1) obtained using a dimethylformamide- $d_{6}$ solvent.

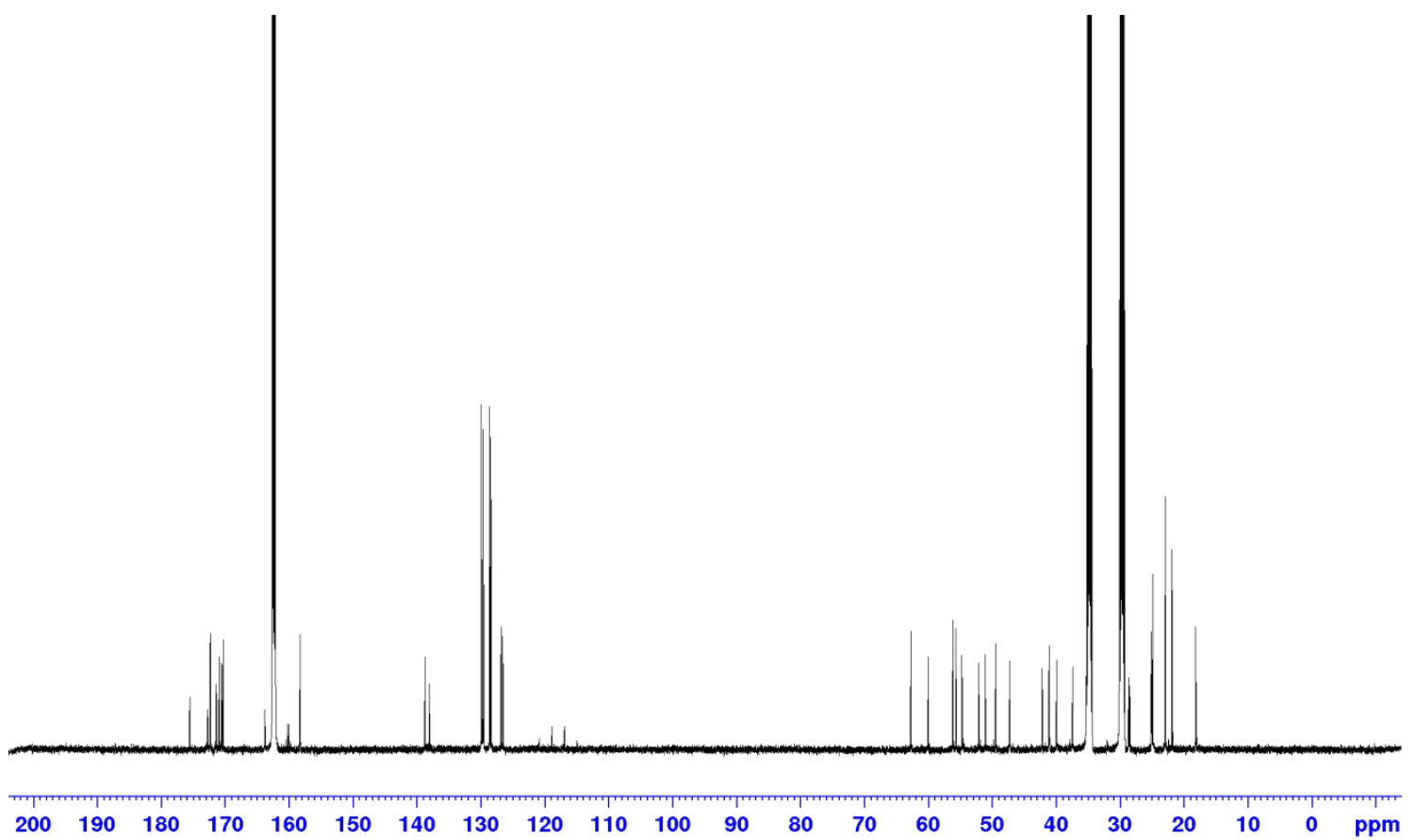

Supplementary Figure 12. ${ }^{13} \mathrm{C}$ NMR spectra (600 MHz) for E1-3 peptide (1) obtained using a dimethylformamide- $\mathrm{d}_{6}$ solvent. 
Val-Gly-Gly-Leu-Ser-His-Arg (Peptide E1-7)

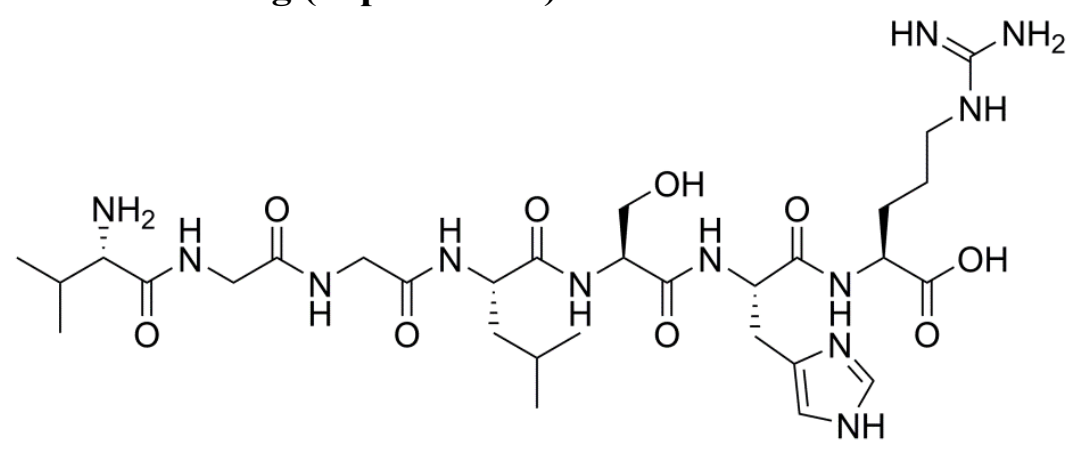

A

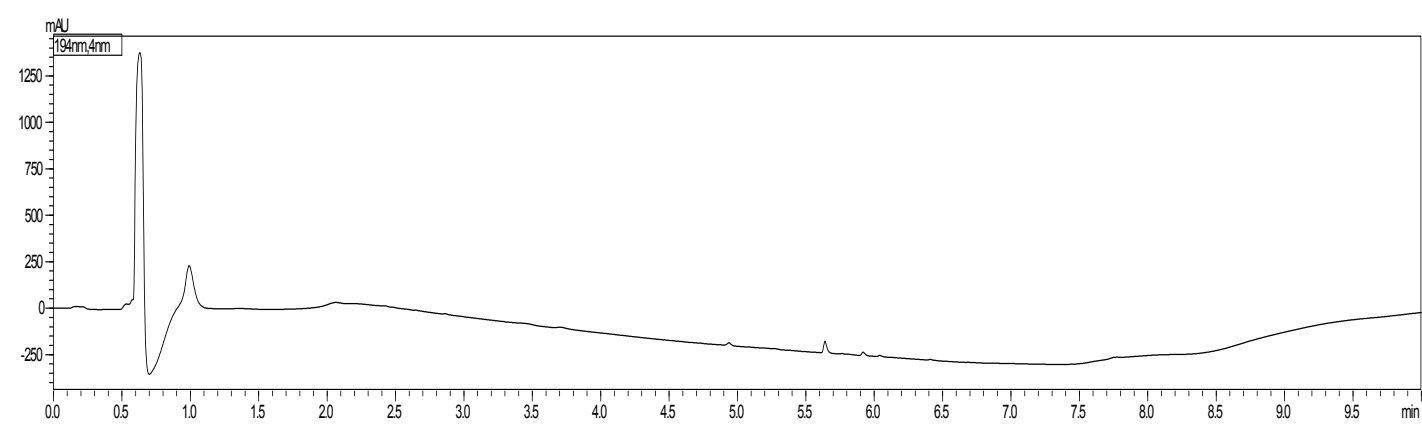

B

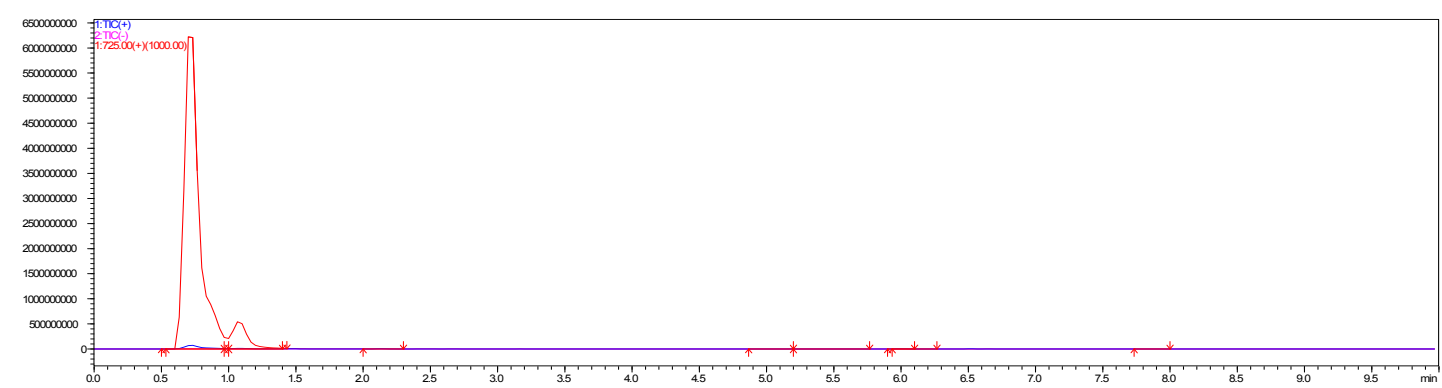

C Inten. $(x 10,000,000)$

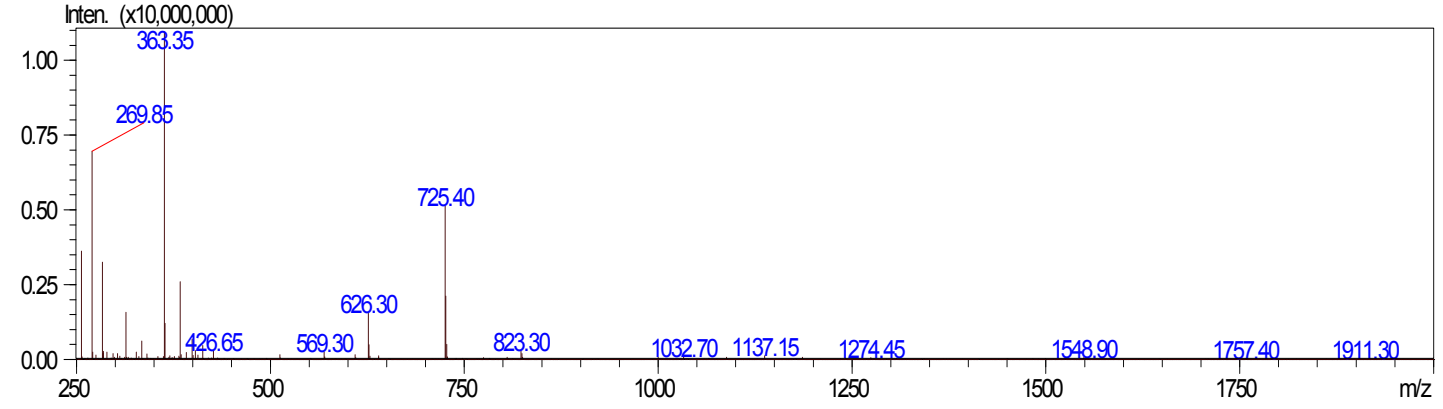

Supplementary Figure 13. LCMS measurement of E1-7 peptide (2). (A) $U V$ chromatogram of Peptide E1-7, (B) Mass spectrometry total ion count for $m / z$ 725.40, which matches with the $[\mathrm{M}+\mathrm{H}]^{+}$for E1-7 peptide (2). (C) Mass spectra of E1-7 peptide (2). 


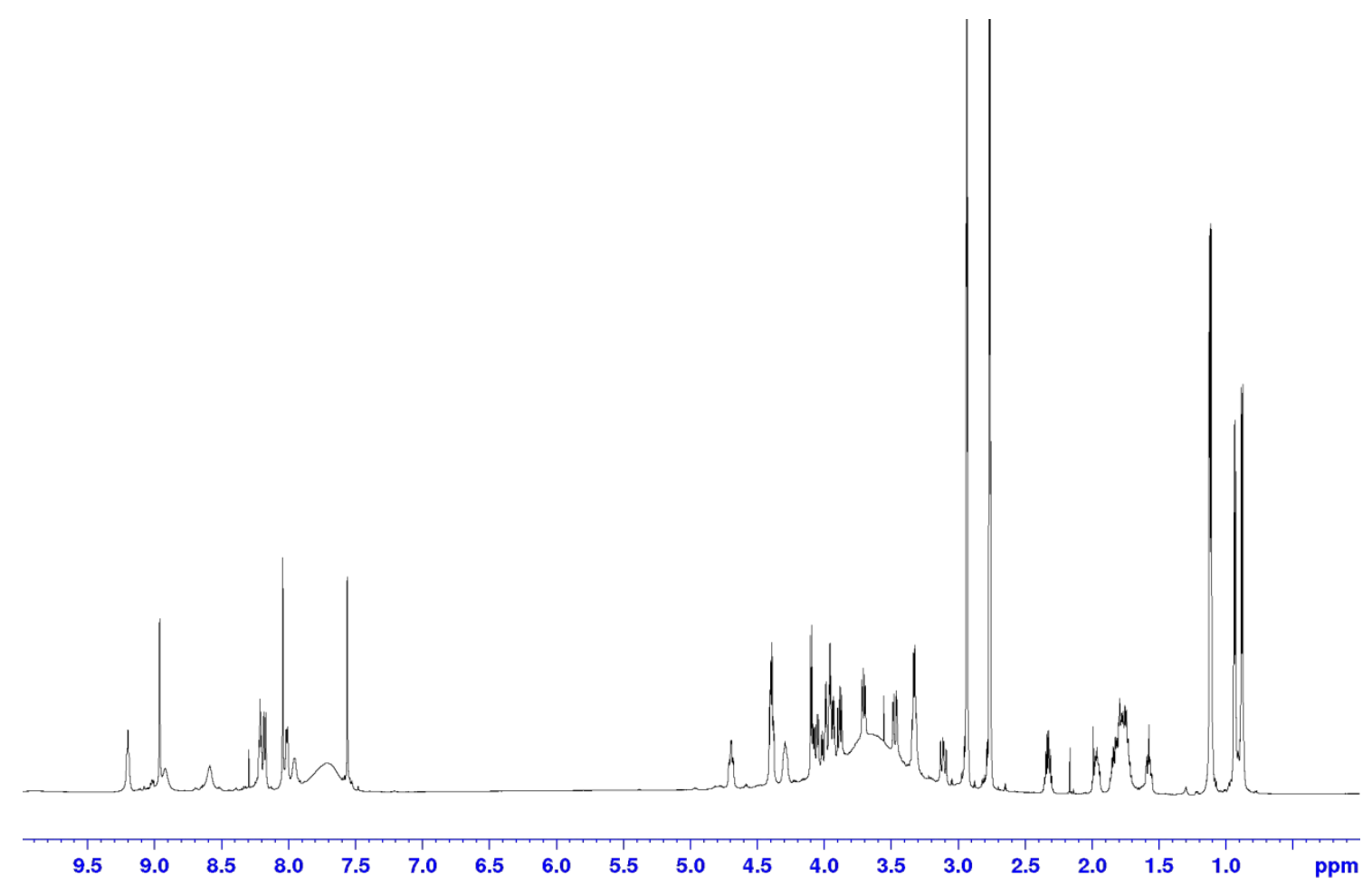

Supplementary Figure 14. ${ }^{1} \mathrm{H}$ NMR spectra (600 MHz) for E1-7 peptide (2) obtained using a dimethylformamide- $d_{6}$ solvent.

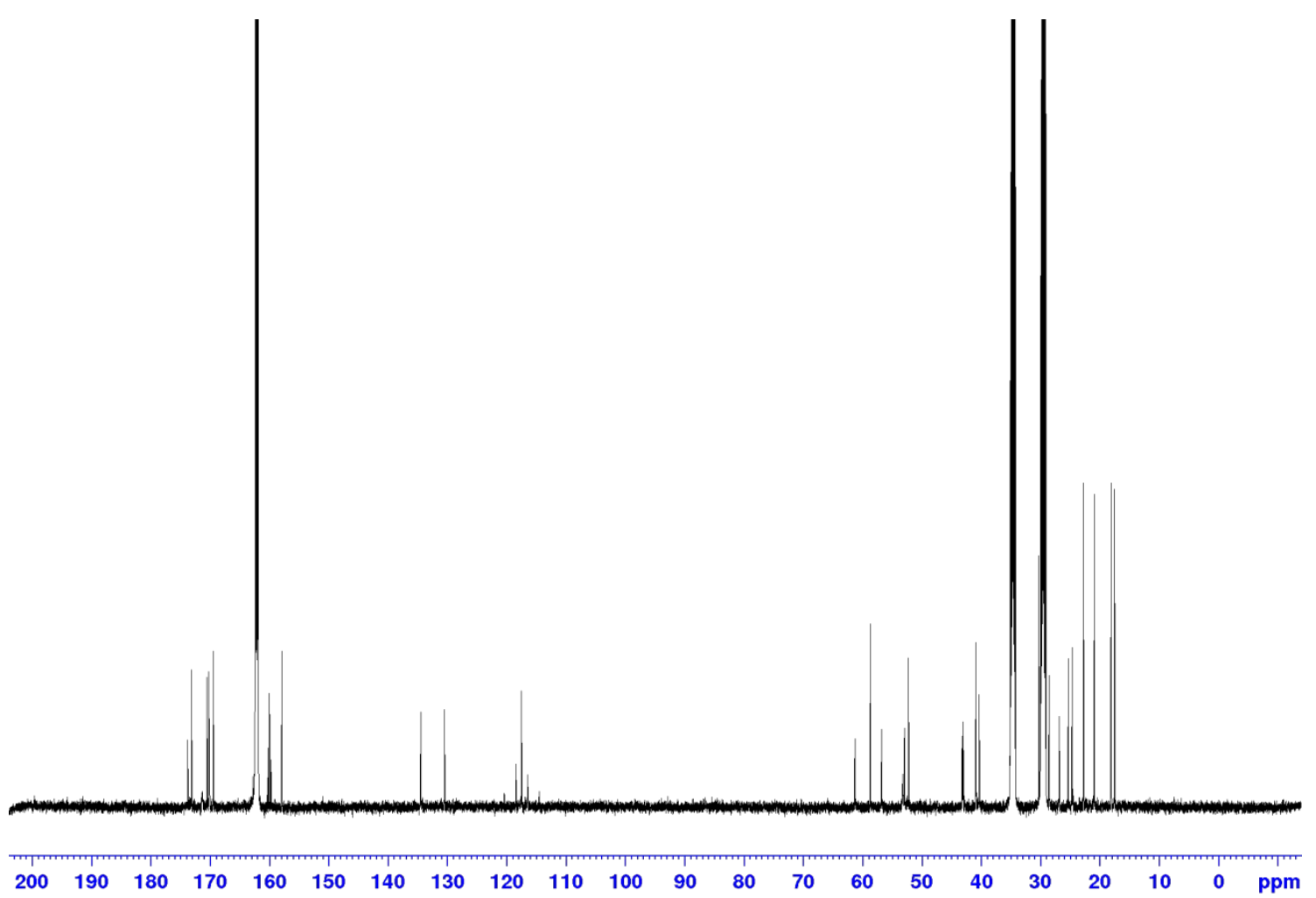

Supplementary Figure 15. ${ }^{13} \mathrm{C}$ NMR spectra (600 MHz) for E1-7 peptide (2) obtained using a dimethylformamide- $\mathrm{d}_{6}$ solvent. 


\section{Characterization Data of Peptide-Drug Conjugates}

\section{E1-3 doxorubicin (3)}

${ }^{1} \mathrm{H}$ NMR (600 MHz, DMF-d $\left.{ }_{6}\right): \delta 8.27-8.06(\mathrm{~m}, 4 \mathrm{H}), 8.00-7.93(\mathrm{~m}, 2 \mathrm{H}), 7.76-7.70(\mathrm{~m}, 1 \mathrm{H})$, 7.41-7.15 (m, 12H), 5.47-5.32 (m, 1H), 5.33-5.23 (m, 1H), 5.14 (s, 1H), 4.78-4.65 (m, 1H), 4.55-4.45 (m, 3H), 4.41-4.33 (m, 1H), 4.30-4.17 (m, 2H), $4.10(\mathrm{~s}, 4 \mathrm{H}), 3.85(\mathrm{dd}, 3 \mathrm{H}, J=5.28$ and $11.04 \mathrm{~Hz}$ ), 3.78 (br s, 2H), $3.73(\mathrm{dd}, 4 \mathrm{H}, J=4.92$ and $11.10 \mathrm{~Hz}), 3.68-3.61(\mathrm{~m}, 3 \mathrm{H}), 3.34$ $(\mathrm{dd}, 1 \mathrm{H},, J=3.78$ and $14.01 \mathrm{~Hz}), 3.26-3.13(\mathrm{~m}, 4 \mathrm{H}), 3.05-2.95(\mathrm{~m}, 1 \mathrm{H}), 2.39-2.34(\mathrm{~m}, 1 \mathrm{H})$, 2.30-2.19 (m, 1H), 2.12-2.02 (m, 1H), 2.02-1.86 (m, 4H), 1.85-1.78 (m, 1H), 1.76-1.56 (m, 4H), $1.30(\mathrm{dd}, 4 \mathrm{H}, J=6.90$ and $32.49 \mathrm{~Hz}), 0.91(\mathrm{dd}, 6 \mathrm{H}, J=6.54$ and $13.32 \mathrm{~Hz}) \mathrm{ppm} .{ }^{13} \mathrm{C}$ NMR (600 MHz, DMF-d 6 ): $\delta$ 187.0, 186.9, 176.8, 172.4, 172.2, 172.1, 171.8, 171.0, 170.6, $170.1,169.8,164.9,159.3,159.1,156.6,155.2,138.9,138.5,136.3,135.5,135.2,134.2$, $129.4,129.2,128.3,128.2,126.3,120.5,119.8,119.7,119.2,111.2,111.1,100.3,76.0,70.0$ $66.9,65.8,62.5,59.4,56.5,55.7,55.1,54.8,54.7,53.1,50.1,49.1,47.5,47.0,43.2,40.9$, $37.7,36.8,36.4,32.8,32.5,27.5,25.0,24.8,22.8,22.3,21.0,18.6,16.6$ ppm. HRMS $\left(\mathrm{ESI}^{+}\right)$ $m / z:[\mathrm{M}+\mathrm{Na}]^{+}$calculated for $\mathrm{C}_{73} \mathrm{H}_{93} \mathrm{~N}_{11} \mathrm{O}_{22} \mathrm{Na}^{+}:$1498.6322, found 1498.6382; $[\mathrm{M}+\mathrm{H}+$ $\mathrm{Na}]^{2+}$ calculated for $\mathrm{C}_{73} \mathrm{H}_{94} \mathrm{~N}_{11} \mathrm{O}_{22} \mathrm{Na}^{+}$: 749.8232, found 749.8226. IR (ATR): $v_{\max } 3227(\mathrm{w})$, $2940(\mathrm{w}), 2191(\mathrm{w}), 1984(\mathrm{~s}) 1633(\mathrm{~m}), 1522(\mathrm{~m}), 1444$ (m), 1201 (s), $1118(\mathrm{~s})$. 


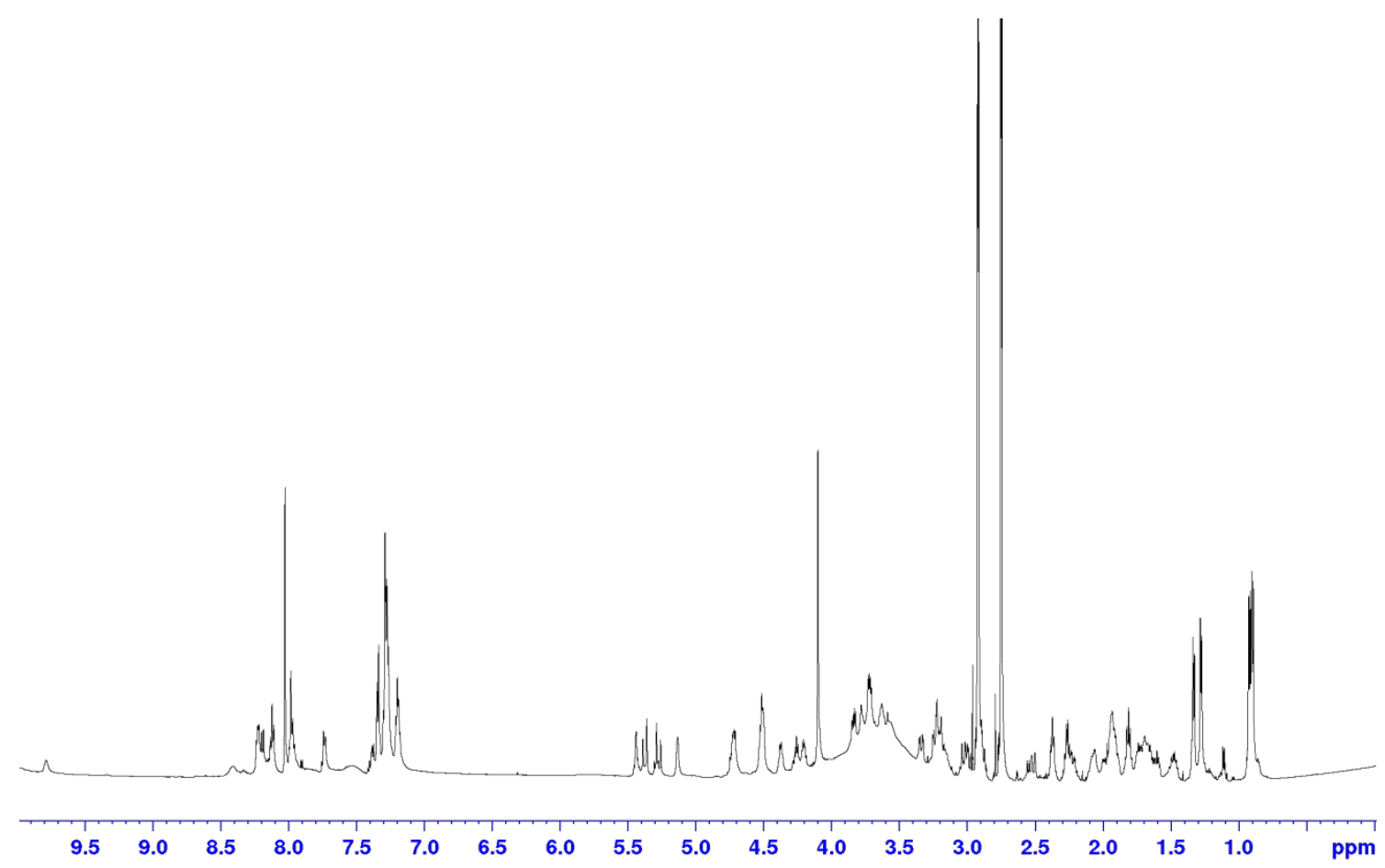

Supplementary Figure 16. ${ }^{1} \mathrm{H}$ NMR spectra (600 MHz) for E1-3 doxorubicin (3) obtained using a dimethylformamide- $\mathrm{d}_{6}$ solvent.

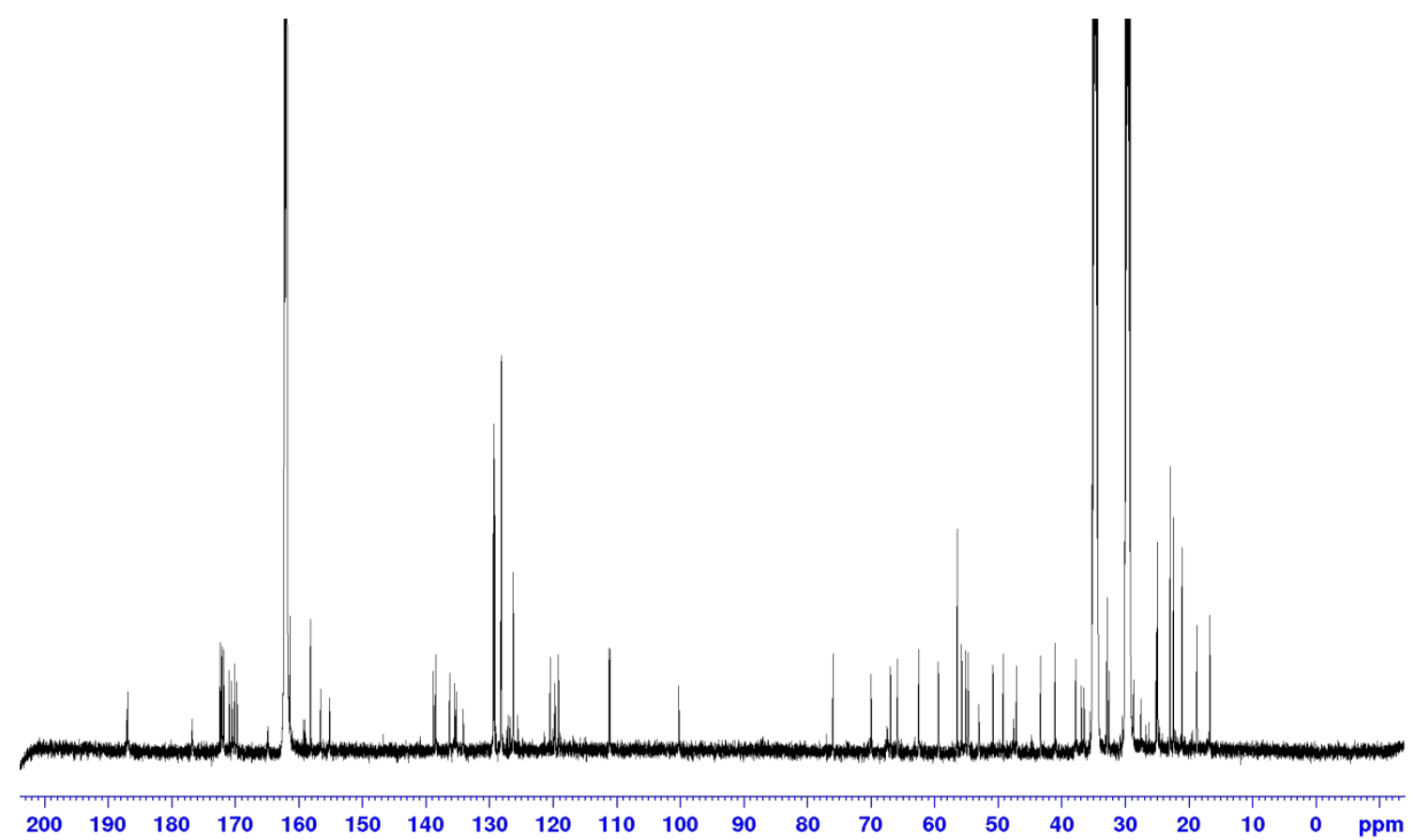

Supplementary Figure 17. ${ }^{13} \mathrm{C}$ NMR spectra (600 MHz) for E1-3 doxorubicin (3) obtained using a dimethylformamide-d ${ }_{6}$ solvent. 


\section{E1-7 doxorubicin (4)}

${ }^{1} \mathrm{H}_{\mathrm{NMR}}\left(600 \mathrm{MHz}, \mathrm{DMF}-\mathrm{d}_{6}\right): \delta 8.35$ (s, 2H), 8.23-8.14 (m, 2H), 8.10-8.04 (m, 2H), 7.98$7.92(\mathrm{~m}, 3 \mathrm{H}), 7.91-7.85$ (br s, 2H), 7.77-7.63 (m, 8H), $6.92(\mathrm{~s}, 1 \mathrm{H}), 5.47-5.35(\mathrm{~m}, 2 \mathrm{H}), 5.33-$ $5.24(\mathrm{~m}, 1 \mathrm{H}), 4.63-4.55(\mathrm{~m}, 1 \mathrm{H}), 4.44-4.37(\mathrm{~m}, 3 \mathrm{H}), 4.22(\mathrm{t}, 2 \mathrm{H}, J=7.25 \mathrm{~Hz}), 4.08(\mathrm{~s}, 4 \mathrm{H})$, 3.13-3.07 (m, 4H), 2.55-2.47 (m, 6H), 2.45-2.39 (m, 4H), 2.22-2.08 (m, 5H), 1.95-1.88 (m, $5 \mathrm{H}), 1.86-1.77(\mathrm{~m}, 3 \mathrm{H}), 1.72-1.49(\mathrm{~m}, 13 \mathrm{H}), 1.27(\mathrm{~d}, 6 \mathrm{H}, J=6.03), 0.95(\mathrm{dd}, 10 \mathrm{H}, J=3.54$ and $\left.6.66 \mathrm{~Hz}, J_{2}=6.88 \mathrm{~Hz}\right), 0.88(\mathrm{dd}, 12 \mathrm{H}, J=6.61$ and $16.59 \mathrm{~Hz}) \mathrm{ppm} .{ }^{13} \mathrm{C} \mathrm{NMR}(600 \mathrm{MHz}$, DMF-d $\left.{ }_{6}\right): \delta 172.7,170.3,159.0,157.1,135.3,116.9,62.1,59.2,56.5,53.6,52.1,42.8,40.9$, 32.9, 25.5, 24.5, 22.8, 21.1, 20.4, 19.0, 18.0, 17.1, 13.7 ppm. HRMS $\left(\mathrm{ESI}^{+}\right) m / z:[\mathrm{M}+\mathrm{H}]^{+}$ calculated for $\mathrm{C}_{62} \mathrm{H}_{86} \mathrm{~N}_{13} \mathrm{O}_{22}: 1364.5973$, found 1364.6010; $[\mathrm{M}+2 \mathrm{H}]^{2+}$ calculated for $\mathrm{C}_{62} \mathrm{H}_{87} \mathrm{~N}_{13} \mathrm{O}_{22}:$ 682.8023, found 682.8032; $[\mathrm{M}+\mathrm{H}+\mathrm{Na}]^{2+}$ calculated for $\mathrm{C}_{62} \mathrm{H}_{86} \mathrm{~N}_{13} \mathrm{O}_{22} \mathrm{Na}^{+}$: 693.7932, found 693.7940. IR (ATR): $v_{\max } 2913$ (m), 1640 (m) 1456 (s), 1375 (s). 


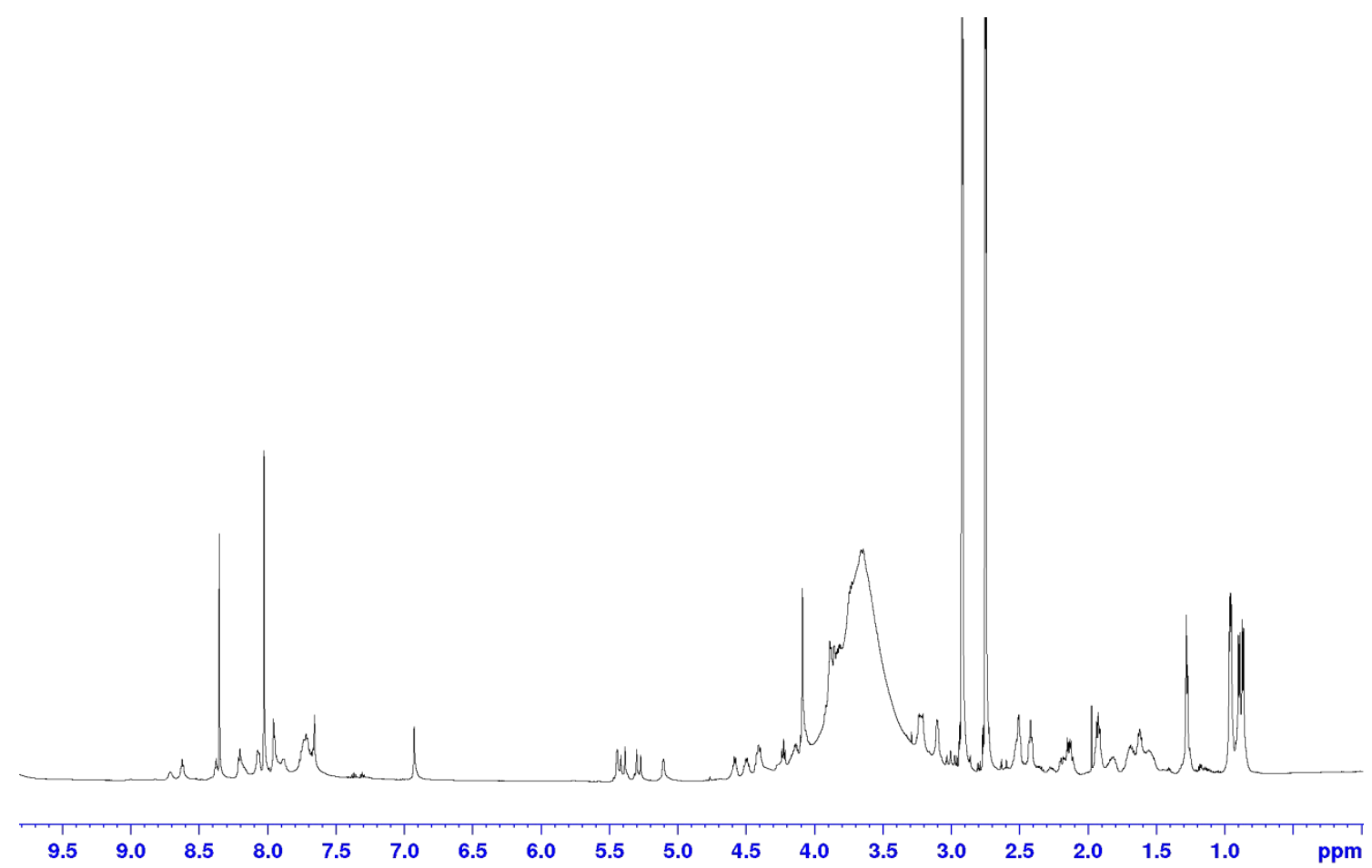

Supplementary Figure 18. ${ }^{1} \mathrm{H}$ NMR spectra (600 MHz) for E1-7 doxorubicin (4) obtained using a dimethylformamide- $\mathrm{d}_{6}$ solvent.

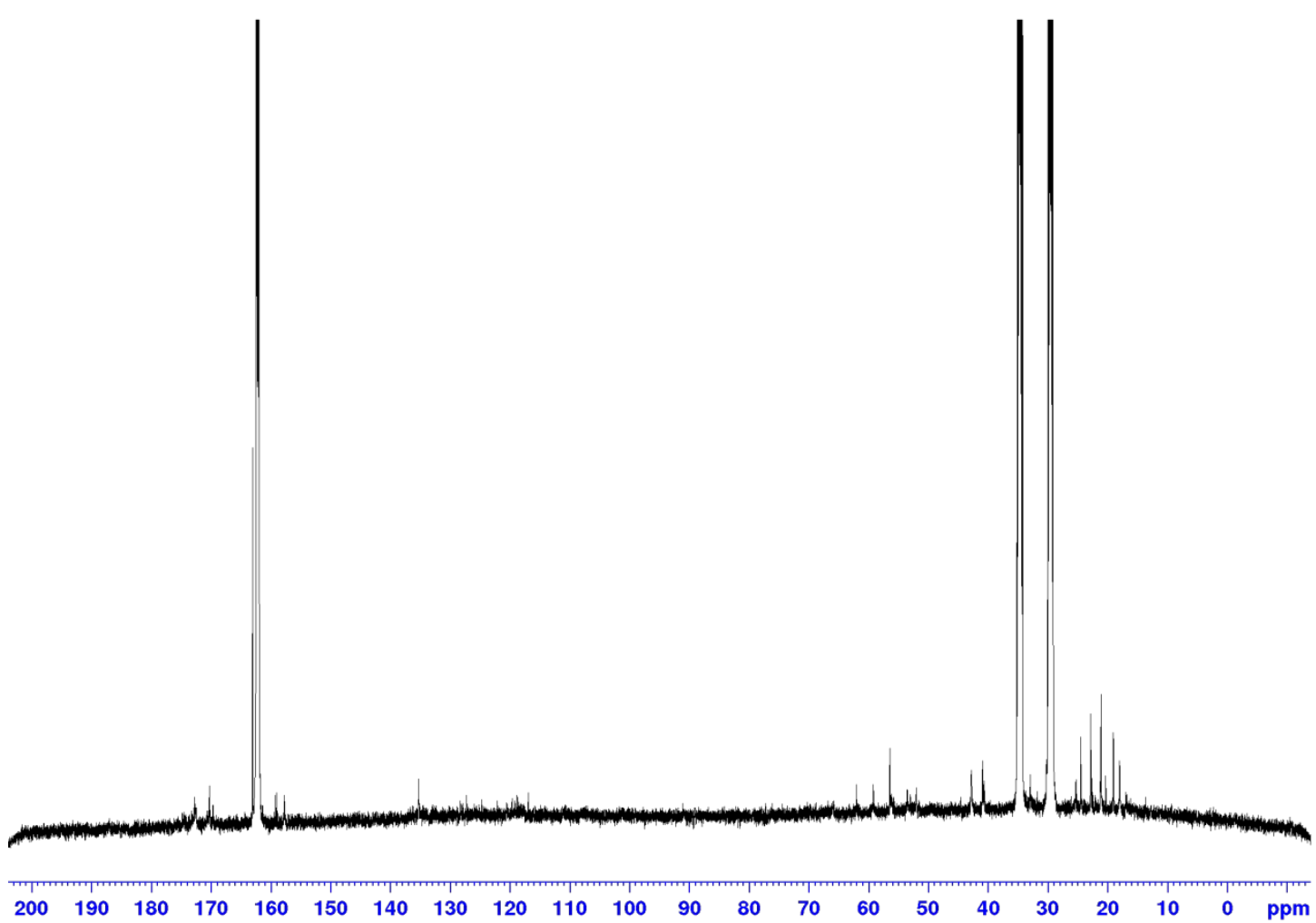

Supplementary Figure $19 .{ }^{13} \mathrm{C}$ NMR spectra (600 MHz) for E1-7 doxorubicin (4) obtained using a dimethylformamide-d ${ }_{6}$ solvent. 